\title{
Permeabilizing action of polyethyleneimine on Salmonella typhimurium involves disruption of the outer membrane and interactions with lipopolysaccharide
}

\author{
Ilkka M. Helander, ${ }^{1}$ Kyösti Latva-Kala ${ }^{1}$ and Kari Lounatmaa ${ }^{2}$ \\ Author for correspondence: Ilkka M. Helander. Tel: +3589456 4452. Fax: +35894552028. \\ e-mail: ilkka.helander@vtt.fi
}

1 VTT Biotechnology and Food Research, PO Box 1501, FIN-02044 VTT, Espoo, Finland

2 Institute of Biotechnology, Electron Microscopy, University of Helsinki, PO Box 56, FIN-00014, Finland

\begin{abstract}
Polyethyleneimine (PEI), a polycationic polymer substance used in various bioprocesses as a flocculating agent and to immobilize enzymes, was recently shown to make Gram-negative bacteria permeable to hydrophobic antibiotics and to detergents. Because this suggests impairment of the protective function of the outer membrane (OM), the effect of PEI on the ultrastructure of Salmonella typhimurium was investigated. Massive alterations in the OM of PEl-treated and thin-sectioned bacteria were observed by electron microscopy. Vesicular structures were seen on the surface of the OM, but no liberation of the membrane or its fragments was evident. Since a potential mechanism for the action of PEI could be its binding to anionic LPSs on the OM surface, the interaction of PEI with isolated LPSs was assayed in vitro. The solubility of smooth-type LPSs of Salmonella, regardless of the sugar composition of their O-specific chains, was not affected by PEI, nor was that of Ra-LPS (lacking Ospecific chains but having a complete core oligosaccharide). PEI strongly decreased the solubility of rough-type LPSs of the chemotypes $R b 2$ and $R e$, whereas it had only a weak effect on the abnormally cationic Rb2-type pmrA mutant LPS, suggesting that the negative charge to mass ratio of LPS plays a critical role in the interaction.
\end{abstract}

Keywords: polyethyleneimine, Gram-negative bacteria, outer membrane, lipopolysaccharide, Salmonella typhimurium

\section{INTRODUCTION}

It was shown recently that polyethyleneimine (PEI), a non-toxic aliphatic and cationic polymeric substance used in various bioprocesses as a flocculating agent and to immobilize enzymes, possesses strong permeabilizing activity on Gram-negative bacteria (Helander et al., 1997). Bacterial species such as Escherichia coli, Pseudomonas aeruginosa and Salmonella typhimurium were effectively sensitized to the detergent SDS and to hydrophobic antibiotics by PEI in p.p.m. concentrations. However, PEI did not exert any direct bactericidal effect on Gram-negative bacteria when applied alone, even in concentrations far above those required for sensitization. These findings strongly suggest that the outer

Abbreviations: OM, outer membrane; PEl, polyethyleneimine; PMBN, polymyxin B nonapeptide. membrane $(O M)$ is functionally disintegrated by PEI, since the OM normally acts as a permeability barrier towards external hydrophobic solutes and detergents (Vaara, 1992). Permeabilizing agents that lack intrinsic toxicity are useful in sensitizing harmful bacteria towards bactericidal substances in, for example, disinfection or food protection.

Many polycationic substances act as permeabilizers by virtue of their ability to release LPS from the OM, the function of which as a permeability barrier is largely attributed to the LPS layer forming its outer leaflet. Accordingly, the sensitizing action of protamine and certain polylysines to antibiotics involves liberation of considerable proportions of LPS from the OM of $S$. typhimurium; the consequent disruption of the OM has been revealed by electron microscopy (Vaara \& Vaara, $1983 \mathrm{a}, \mathrm{b})$. Various other polycations, such as polymyxin $\mathrm{B}$ nonapeptide (PMBN), permeabilize the OM without 


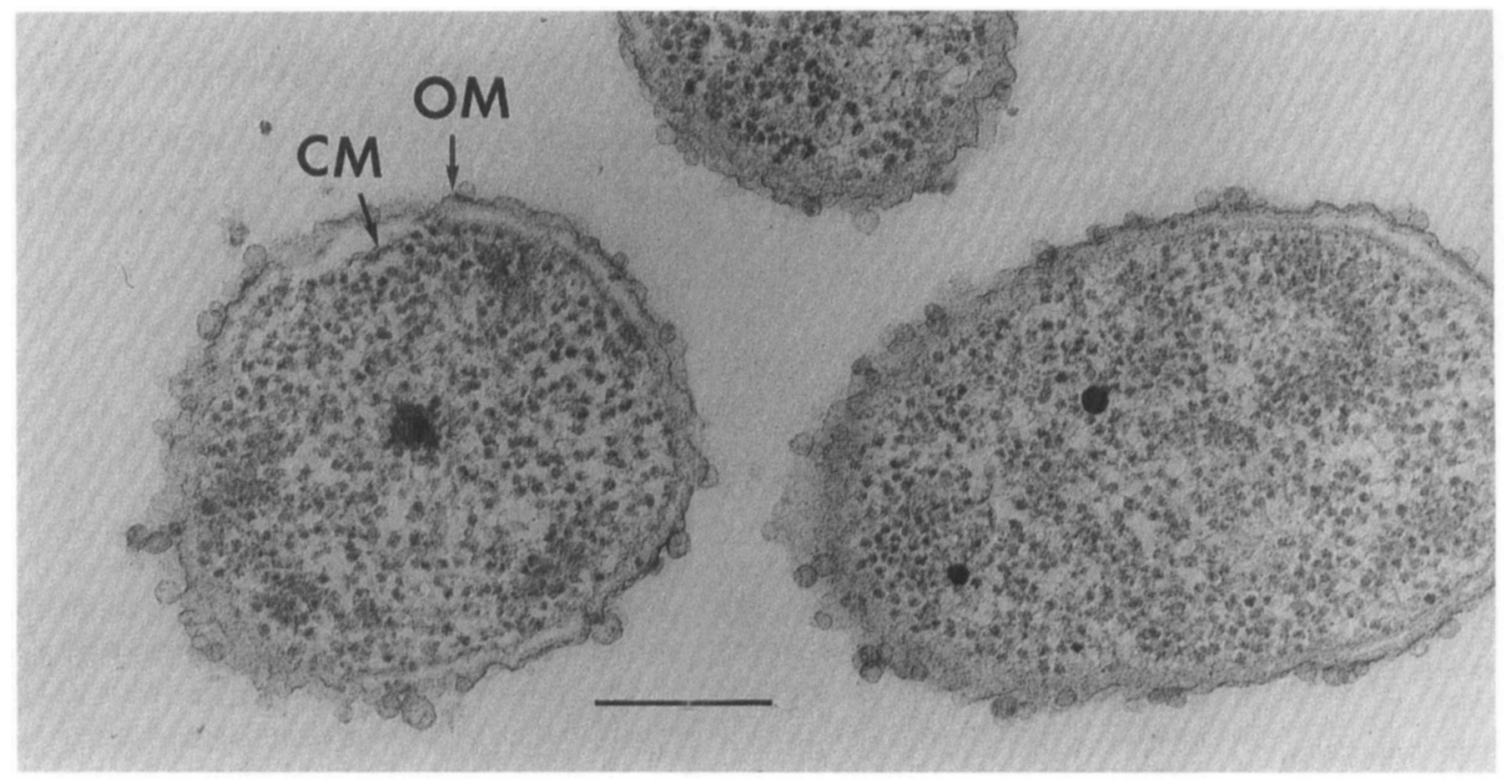

Fig. 1. Cells of S. typhimurium ATCC 13311 (smooth-type strain) treated with PEI (10 $\left.\mu \mathrm{g} \mathrm{ml}^{-1}\right)$. CM, cytoplasmic membrane. Bar, $0.2 \mu \mathrm{m}$.

significant liberation of LPS (Vaara \& Vaara, 1983b). In this respect, PEI and PMBN proved to be similar, as no liberation of LPS was detected in our assays in which PEI acted on S. typhimurium; however, the possibility of PEI forming poorly soluble complexes with LPS and hence preventing the detection of released LPS remained open (Helander et al., 1997). In the present study, we have explored the mechanism of action of PEI, looking for direct evidence of its effects on the OM. We have investigated the effect of PEI treatment on the ultrastructure of $S$. typhimurium and assayed the interactions of various purified LPSs of $S$. typhimurium with PEI.

\section{METHODS}

Chemicals. PEI (mean molecular mass $50000 \mathrm{Da}$ ) and nheptadecanoic acid methyl ester were obtained from Sigma. Glutaraldehyde was purchased from Merck.

Bacterial strains, their cultivation and preparation for electron microscopy. Salmonella typhimurium strains ATCC 13311 (LPS chemotype S, O:4,5,12; for LPS chemotypes, see Helander et al., 1996) and SH5014 (Stocker et al., 1979; LPS chemotype $\mathrm{Rb} 2$ ) were used in the electron microscopy studies. They were grown in LB broth $(10 \mathrm{~g}$ Difco tryptone, $5 \mathrm{~g}$ Difco

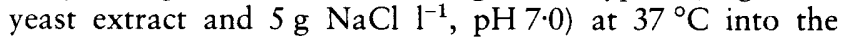
exponential phase of growth $\left(\mathrm{OD}_{630} 0.4\right.$; Multiskan $\mathrm{MCC} / 340$ spectrophotometer), and the cultures were centrifuged at $3000 \mathrm{~g}\left(10 \mathrm{~min}, 21^{\circ} \mathrm{C}\right)$. The deposited cells were then suspended in a similar volume of $10 \mathrm{mM}$ Tris/ $\mathrm{HCl}$ buffer ( $\mathrm{pH} 7 \cdot 2$ ), centrifuged as above, and again suspended in Tris buffer, to which PEI or EDTA was added to yield concentrations of $10 \mu \mathrm{g} \mathrm{ml}^{-1}$ and $1 \mathrm{mM}$, respectively. After the cell suspensions had been kept for $10 \mathrm{~min}$ at $37^{\circ} \mathrm{C}$, portions were centrifuged at 11000 r.p.m. ( $1 \mathrm{~min}, 21^{\circ} \mathrm{C}$; Biofuge 13 , Heraeus Instruments) and the cell pellets were resuspended in $5 \mathrm{mM}$ HEPES buffer ( $\mathrm{pH} 7 \cdot 2$ ) containing $2.5 \%(\mathrm{v} / \mathrm{v})$ glutaraldehyde.
After $1 \mathrm{~h}$ at $21^{\circ} \mathrm{C}$, the cells were recovered by centrifugation and stored at $4^{\circ} \mathrm{C}$ in $5 \mathrm{mM}$ HEPES (pH 7.2).

Electron microscopy. After the pre-fixation with glutaraldehyde described above, the samples for thin-sectioning were prepared as described by Lounatmaa (1985). Electron micrographs were taken with a JEM-1200EX transmission electron microscope (JEOL) at $60 \mathrm{kV}$.

LPSs. Extraction of LPS from the smooth S. typhimurium strains SH2183 (Valtonen, 1970) and SH5770 (Valtonen, 1977) by the aqueous $45 \%$ phenol method has been described previously (Helander et al., 1992). SH5770 is a recombinant strain carrying $O$ antigen 6,7 instead of the normal $O: 4,5,12$ antigen present in SH2183 (Valtonen, 1977). LPSs from the rough-type strains his-515 (LPS chemotype Ra ; Nikaido et al., 1967), SH5014 (Rb2), SH7426 (Rb2, pmrA mutant elaborating exceptionally cationic LPS; Vaara, 1981; Helander et al., 1994) and SL1102 (Re; Wilkinson et al., 1972) were extracted by the phenol/chloroform/light petroleum (boiling point range $40-60^{\circ} \mathrm{C}$ ) method (Galanos et al., 1969). Each LPS was converted to its triethylammonium salt for maximal water solubility (Galanos \& Lüderitz, 1975), and stock solutions ( $2 \mathrm{mg} \mathrm{ml}^{-1}$ ) in water were prepared.

LPS solubility assay. Pairs of LPS solutions containing $0.6 \mathrm{mg}$ LPS in $1 \mathrm{ml}$ water were prepared in microfuge vials, and one vial of each pair was supplemented with PEI at $20 \mu \mathrm{g} \mathrm{ml}^{-1}$. The other served as a control. After the solutions had been mixed at $21^{\circ} \mathrm{C}$, the vials were centrifuged at 11000 r.p.m. for $4 \mathrm{~min}$ at $21^{\circ} \mathrm{C} ; 800 \mu \mathrm{l}$ supernatant was removed and freeze-dried in $20 \mathrm{ml}$ headspace vials. To the dry samples, $105 \mu \mathrm{g}$ n-heptadecanoic acid methyl ester was added, and the samples were processed for fatty acid analysis by saponification and methylation as described by Moore et al. (1994). The fatty acid methyl esters were analysed by GLC as described previously (Helander et al., 1997). The amounts of LPS-specific fatty acids (dodecanoic acid, tetradecanoic acid, hexadecanoic acid and 3-hydroxytetradecanoic acid for Salmonella LPS; see Zähringer et al., 1994) in the supernatants of PEI-containing 
and control samples were compared to determine the LPSprecipitating activity of PEI $(100 \%=$ total precipitation of LPS). Each assay was performed twice. It was shown separately that mere centrifugation of aqueous solutions of LPS deposited less than $10 \%$ of the total LPS.

\section{RESULTS}

\section{Effect of PEI on bacterial ultrastructure}

The effect of PEI treatment on the ultrastructure of $S$. typhimurium strains ATCC 13311 and SH5014 was investigated by thin-section electron microscopy. The general effect of PEI on bacterial ultrastructure is seen in Fig. 1, where the OM of S. typhimurium ATCC 13311 is abnormal. Strong undulation of the membrane is evident, and membrane vesicles are prominently present. The cytoplasmic membrane appears to be unaffected, at least at the resolution of thin-section electron microscopy. The effect of PEI on the smooth S. typhimurium strain can be seen in more detail in Fig. 2, in which the
OM of untreated cells (Fig. 2a) is rather even with minor undulation. In the cells treated with PEI (Fig. 2b), prominent undulation and folding of the $O M$ are evident. Cells treated with EDTA (Fig. 2c) looked similar to the control cells.

In a rough strain of $S$. typhimurium (SH5014, LPS chemotype Rb2; Fig. 3), the effects of PEI were similar to those observed for the smooth strain, although vesiculation of PEI-treated cells was less prominent. Control cells of the rough (Fig. 3a) and smooth (Fig. 2a) strains were indistinguishable.

\section{Effect of PEI on the solubility of isolated LPS}

LPS molecules are normally polyanionic due to phosphate and carboxyl groups in the lipid A and inner core oligosaccharide (Helander et al., 1996). For this reason, they tend to bind cations, among them metals, oligoand polyamines (Galanos \& Lüderitz, 1975), polymyxin
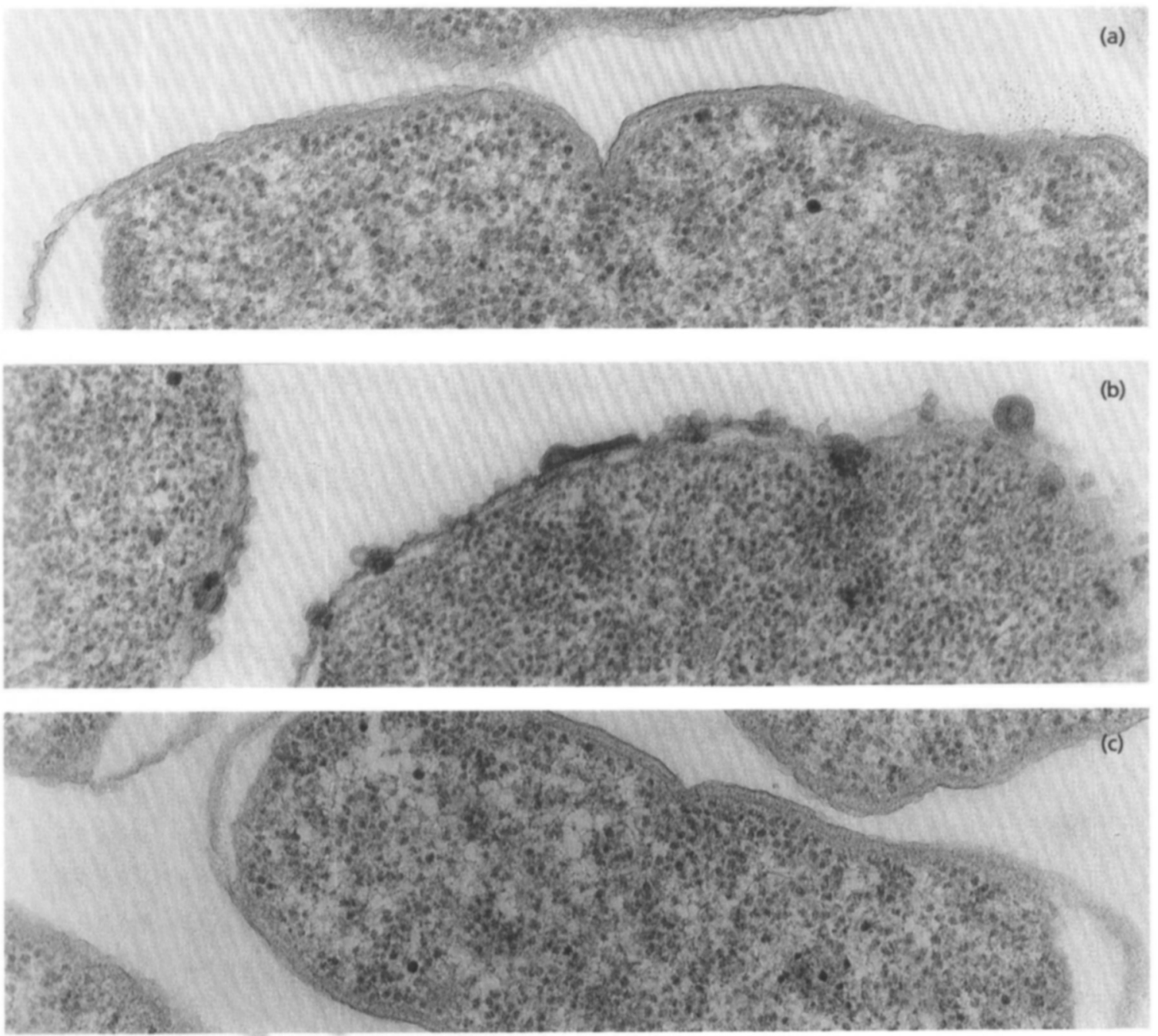

Fig. 2. Cell envelope of (a) untreated, (b) PEl-treated $\left(10 \mu \mathrm{g} \mathrm{ml}^{-1}\right)$ and (c) $1 \mathrm{mM}$ EDTA-treated S. typhimurium ATCC 13311. Scale as in Fig. 1. 

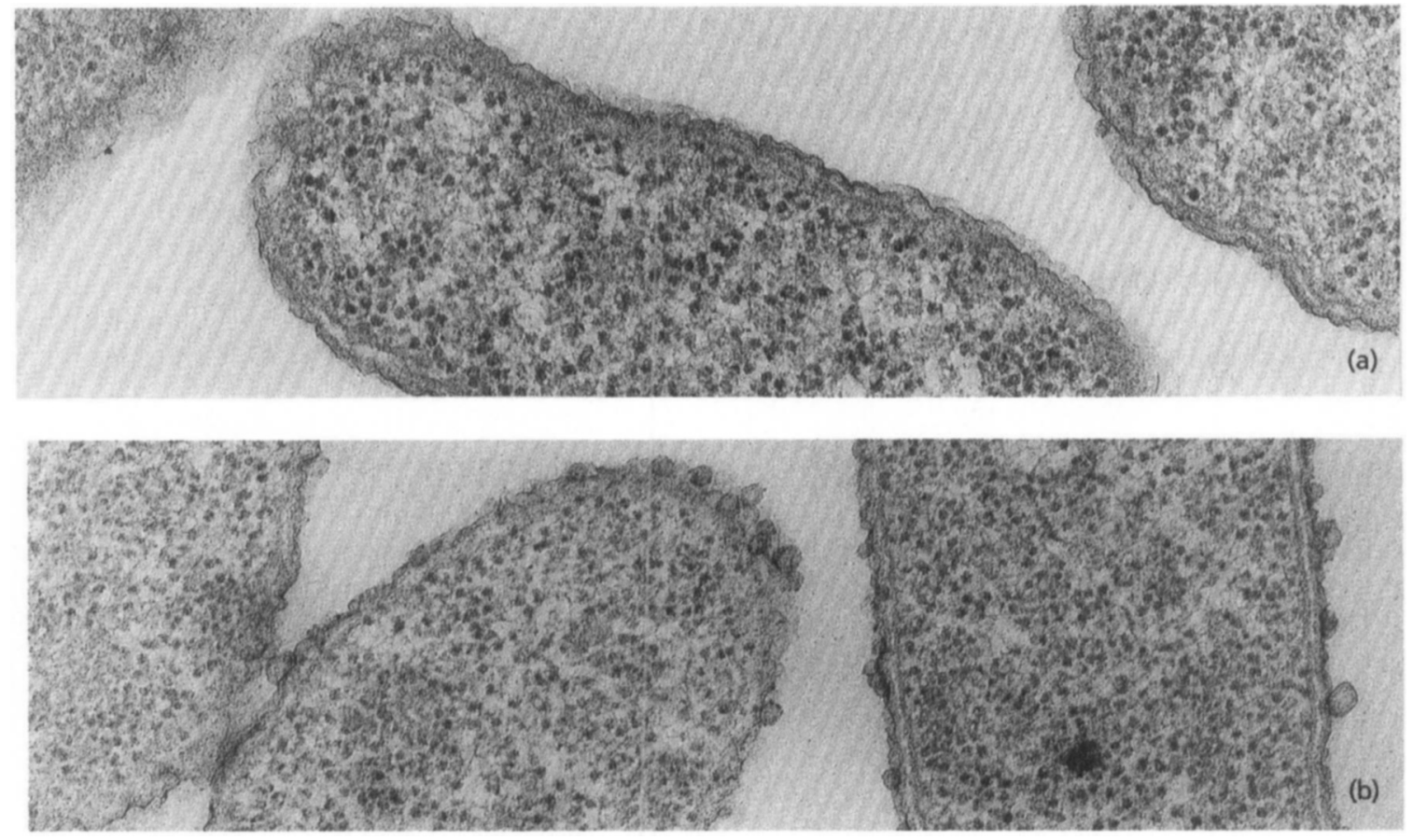

Fig. 3. Cell envelope of (a) untreated and (b) PEl-treated $\left(10 \mu \mathrm{g} \mathrm{ml}^{-1}\right)$ rough strain SH5014 of S. typhimurium. Scale as in Fig. 1.

B and deacylated polymyxin B (Vaara, 1983). Since the polycationic PEI functionally and ultrastructurally altered the OM, its action could be mediated by binding to LPS, especially since PEI binds to and flocculates biological materials (Milburn et al., 1990; Salt et al., 1995). We tested whether isolated and purified LPS interacts with PEI in aqueous solutions. Highly soluble triethylammonium salt forms of different $S$. typhimurium LPS were mixed with PEI $\left(20 \mu \mathrm{g} \mathrm{m}^{-1}\right)$ and centrifuged to deposit any poorly soluble products. After centrifugation, the LPS remaining in solution was quantified by analysing the amount of LPS-specific fatty acids in the supernatant. Similarly centrifuged LPS solutions without PEI were assayed as controls. The results are shown in Table 1.

The solubility of the LPS of S. typhimurium SH2183 and SH5770 was not affected by PEI. These LPSs are of the smooth chemotype, containing dozens of repeating oligosaccharide units (O-specific chains), and they were chosen because their $\mathrm{O}$-specific chains are different. The repeating units of SH2183 consist of D-mannose, Lrhamnose, D-galactose, 3,6-dideoxy-D- $x y l o$-hexose and, partially, D-glucose (O specificity 4,5,12; Hellerqvist $e t$ al., 1969) whereas in SH5770 the repeating units are genetically replaced by the $\mathrm{O}: 6,7$-specific type consisting of four molecules of D-mannose and one $\mathrm{N}$-acetylglucosamine, with one D-mannose unit being partially substituted by D-glucose (Lindberg et al., 1988). These $\mathrm{O}$-chains differ in their content of deoxy-sugars and hence in their relative hydrophilicity, and they were
Table 1. Effect of PEI on the solubility of isolated LPS of S. typhimurium strains

\begin{tabular}{|llc|}
\hline Strain & $\begin{array}{c}\text { Chemotype } \\
\text { (O-antigenic type, } \\
\text { relevant genotype) }\end{array}$ & $\begin{array}{c}\text { Proportion of } \\
\text { insoluble LPS after } \\
\text { PEI treatment* }\end{array}$ \\
\hline SH2183 & $\mathrm{S}(\mathrm{O}: 4,5,12)$ & $2 \pm 2$ \\
SH5770 & $\mathrm{S}(\mathrm{O}: 6,7)$ & 0 \\
his-515 & $\mathrm{Ra}$ & $7 \pm 7$ \\
SH5014 & $\mathrm{Rb} 2$ & $79 \pm 13$ \\
SH7426 & $\mathrm{Rb} 2(p m r A)$ & $19 \pm 4$ \\
SL1102 & $\mathrm{Re}$ & $77 \pm 15$ \\
\hline
\end{tabular}

*Determined as percentage (mean \pm SEM) of LPS deposited from PEI-containing LPS solutions (PEI, $20 \mu \mathrm{g} \mathrm{ml}^{-1}$; LPS, $0.6 \mathrm{mg} \mathrm{ml}^{-1}$ ) by a 4 min centrifugation at 11000 r.p.m., as compared to LPS solutions without PEI. Quantification of LPS in the supernatants was performed by analysis of LPS-specific fatty acids.

previously shown to differ in their physico-chemical properties (Helander et al., 1992). Both LPS types remained fully soluble in water in the presence of PEI.

Similarly, the solubility of Ra-type LPS (bis-515, lacking $\mathrm{O}$-specific chains but possessing a complete core oligosaccharide) was unaffected by PEI. More incomplete types of LPS ( $\mathrm{Rb} 2$ and $\mathrm{Re}$ ) did, however, form insoluble complexes with PEI. The Rb2 LPS variant isolated from strain $\mathrm{SH} 7426$ is, due to the $p m r A$ mutation, abnormally 
cationic as a result of extensive substitution of phosphate groups by cationic compounds (Helander et al., 1994). This LPS was only poorly deposited from PEI-containing solution by the centrifugation procedure.

\section{DISCUSSION}

Our results demonstrate that PEI causes massive alterations in the OM. This is consistent with our previous report that PEI-induced sensitization of Gram-negative species to detergents and hydrophobic substances indicates disruption of the permeability barrier function of the OM (Helander et al., 1997). Furthermore, electron microscopy supports the previous finding based on chemical analysis that PEI did not release LPS from the OM. The possibility that liberation of LPS by PEI was obscured by the LPS-precipitating activity of PEI was excluded by our present finding that smooth-type LPS and Ra-LPS were not precipitated by PEI. We conclude that PEI intercalates in the $O M$ and increases the membrane surface area to an extent that can be visualized by electron microscopy.

The action of PEI on the OM resembles that of the deacylated polymyxin derivative PMBN. Without releasing LPS or being directly bactericidal, both substances make the OM permeable to hydrophobic antibiotics, and they cause similar ultrastructural alterations in the OM (Vaara \& Vaara, 1983b). Furthermore, PMBN was reported not to sensitize $S$. typhimurium to SDS (Vaara \& Vaara, 1983b), and this was also noted in experiments where the detergent was present with PEI (Helander et al., 1997). However, PEI strongly sensitized E. coli, $P$. aeruginosa and S. typhimurium to the lytic action of SDS if the bacteria were pretreated with PEI and subsequently challenged with SDS.

The interaction of PEI with purified LPS differed greatly, depending on the macromolecular nature of the LPS. Smooth-type LPS, regardless of the sugar composition of the O-specific chains, and Ra-LPS did not form poorly soluble products with PEI, whereas deeper roughtype LPS did. Precipitation of chemotype Rb2 and Re LPS with PEI seems to be associated with their much higher negative charge to mass ratio compared to that of smooth-type LPS. This is supported by our finding that abnormally cationic pmrA mutant Rb2 LPS was only slightly precipitated by PEI. It should be noted here that the LPS deposition assay measured only the effect of PEI on the solubility of LPS and not the binding itself; thus the results do not exclude the possibility that PEI also binds to smooth LPS without yielding insoluble complexes. To conclude, although PEI evidently does bind to the OM, and has a tendency to bind to LPS, it is possible that its binding to the $\mathrm{OM}$ involves interactions with other membrane components, such as proteins and phospholipids. Phospholipids are normally not present in the outer leaflet of the OM, but they can be accessible after primary disruption of the OM (Vaara, 1992). Bacterial lipids are known to be flocculated by PEI from cellular homogenates (Salt et al., 1995), and it is likely that outer-membrane proteins, many of which possess anionic character (Schmitgess \& Henning, 1976; Tokunaga et al., 1979), also bind to PEI.

\section{ACKNOWLEDGEMENTS}

We thank Päivi Lepistö, Anna-Liisa Ruskeepää and Arja Strandell for excellent technical assistance. Pertti Koski is thanked for valuable discussions. This work was financially supported by the Academy of Finland (to K.L.) and by the NISIN $^{\text {PLUS }}$ project (FAIR-CT96-1148).

\section{REFERENCES}

Galanos, C. \& Lüderitz, O. (1975). Electrodialysis of lipopolysaccharides and their conversion to uniform salt forms. Eur $J$ Biochem 54, 603-610.

Galanos, C., Luderitz, O. \& Westphal, O. (1969). A new method for the extraction of $\mathrm{R}$ lipopolysaccharides. Eur J Biochem 9, 245-249.

Helander, I. M., Hurme, R., Haikara, A. \& Moran, A. P. (1992). Separation and characterization of two chemically distinct lipopolysaccharides in two Pectinatus species. J Bacteriol 174, 3348-3354.

Helander, I. M., Kilpeläinen, I. \& Vaara, M. (1994). Increased substitution of phosphate groups in lipopolysaccharides and lipid A of the polymyxin-resistant pmrA mutants of Salmonella typhimurium: a ${ }^{31} \mathrm{P}-\mathrm{NMR}$ study. Mol Microbiol 11, 481-487.

Helander, I. M., Mäkelä, P. H., Westphal, O. \& Rietschel, E. T. (1996). Lipopolysaccharides. In Encyclopedia of Molecular Biology and Molecular Medicine, vol. 3, pp. 462-471. Edited by R. A. Meyers. Weinheim, New York, Basel, Cambridge \& Tokyo: VCH.

Helander, I. M., Alakomi, H., Latva-Kala, K. \& Koski, P. (1997). Polyethyleneimine is an effective permeabilizer of Gram-negative bacteria. Microbiology 143, 3193-3199.

Hellerqvist, C. G., Lindberg, B., Svensson, S., Holme, T. \& Lindberg, A. A. (1969). Structural studies on the O-specific sidechains of the cell-wall lipopolysaccharide from Salmonella typhimurium LT2. Carbohydr Res 9, 237-241.

Lindberg, B., Leontein, K., Lindqvist, U., Svensson, S. B., Wrangsell, G., Dell, A. \& Rogers, M. (1988). Structural studies of the O-antigenic polysaccharide of Salmonella thompson, serogroup C1 (6,7). Carbohydr Res 174, 313-322.

Lounatmaa, K. (1985). Electron microscopic methods for the study of bacterial surface structures. In Enterobacterial Surface Antigens: Methods for Molecular Characterization, pp. 243-261. Edited by T. K. Korhonen, E. A. Dawes \& P. H. Mäkelä. New York: Elsevier Science.

Milburn, P., Bonnerjea, J., Hoare, M. \& Dunnill, P. (1990). Selective flocculation of nucleic acids, lipids, and colloidal particles from a yeast cell homogenate by polyethyleneimine, and its scale-up. Enzyme Microb Technol 12, 527-532.

Moore, L. V. H., Bourne, D. M. \& Moore, W. E. C. (1994). Comparative distribution and taxonomic value of cellular fatty acids in thirty-three genera of anaerobic gram-negative bacilli. Int $J$ Syst Bacteriol 44, 338-347.

Nikaido, H., Levinthal, M., Nikaido, K. \& Nakane, K. (1967). Extended deletions in the histidine-rough-b region of the Salmonella chromosome. Proc Natl Acad Sci USA 57, 1825-1832.

Salt, D. E., Hay, S., Thomas, O. R. T., Hoare, M. \& Dunnill, P. (1995). Selective flocculation of cellular contaminants from 
soluble proteins using polyethyleneimine; a study of several organisms and polymer molecular weights. Enzyme Microb Technol 17, 107-113.

Schmitgess, C. J. \& Henning, U. (1976). The major proteins of the Escherichia coli outer cell-envelope membrane. Heterogeneity of protein I. Eur J Biochem 63, 47-52.

Stocker, B. A. D., Nurminen, M. \& Măkelä, P. H. (1979). Mutants defective in the $33-\mathrm{K}$ outer membrane protein of Salmonella typhimurium. J Bacteriol 139, 376-383.

Tokunaga, H., Tokunaga, M. \& Nakae, T. (1979). Characterization of porins from the outer membrane of Salmonella typhimurium. 1. Chemical analysis. Eur J Biochem 95, 433-439.

Vaara, M. (1981). Increased outer membrane resistance to ethylenediaminetetraacetate and cations in novel lipid A mutants. J Bacteriol 148, 426-434.

Vaara, M. (1983). Polymyxin B nonapeptide complexes with lipopolysaccharide. FEMS Microbiol Lett 18, 117-121.

Vaara, M. (1992). Agents that increase the permeability of the outer membrane. Microbiol Rev 56, 395-411.

Vaara, M. \& Vaara, T. (1983a). Polycations sensitize enteric bacteria to antibiotics. Antimicrob Agents Chemother 24, 107-113.

Vaara, M. \& Vaara, T. (1983b). Polycations as outer membranedisorganizing agents. Antimicrob Agents Chemother 24, 114-122.

Valtonen, M. V. (1977). Role of phagocytosis in mouse virulence of Salmonella typhimurium recombinants with $\mathrm{O}$ antigen 6,7 or 4,12. Infect Immun 18, 574-582.

Valtonen, V. V. (1970). Mouse virulence of Salmonella strains: the effect of different smooth-type O side-chains. J Gen Microbiol 64, 255-268.

Wilkinson, R. G., Gemski, P., Jr \& Stocker, B. A. D. (1972). Nonsmooth mutants of Salmonella typhimurium: differentiation by phage sensitivity and genetic mapping. J Gen Microbiol 70, $527-554$.

Zähringer, U., Lindner, B. \& Rietschel, E. Th. (1994). Molecular structure of lipid A, the endotoxic center of bacterial lipopolysaccharides. Adv Carbohydr Chem Biochem 50, 211-276.

Received 9 July 1997; revised 19 September 1997; accepted 20 October 1997. 